\title{
PENGARUH GAYA KEPEMIMPINAN, BUDAYA ORGANISASI DAN MOTIVASI KERJA TERHADAP PRESTASI KERJA PEGAWAI DI LEMBAGA PEMASYARAKATAN KELAS IIB TEGAL
}

\author{
Fajar Setiawan dan Tri Jaka Kartana \\ Lapas Slawi, dan Universitas Pancasakti Tegal \\ Email: blozo setiawan@yahoo.com
}

\begin{abstract}
The study is done to test the influence of style leadership, culture organiasasi and motivation work to work performance employees in an institution pemasyarakatan (lapas) a class IIB tegal. Population in research are always 50 people employees lapas kelas iib tegal. Research sample areas in a slovin, then set the sample as many as 44 were employees lapas class IIB tegal. The approach that was used in pene; litian this is the quantitative approach, data is collected through chief the questionnaire research that have been filled by respondents. A method of data analysis used is the method linear regression multiple, with data processing using sofware spss 20.0. The result of this research with this $f$ simultaneous shows that style leadership, culture organization and motivation work together have had a positive impact and significantly to work performance employees. While with this t partial shows that style leadership, culture organization and motivation work haphazardly (partial) have had a positive impact and significantly to work performance employees.
\end{abstract}

Keywords: a style of leadership, cultural organization, motivation work, work performance

\section{PENDAHULUAN}

Lembaga Pemasyarakatan (Lapas) dan Rumah Tahanan (Rutan) merupakan salah satu institusi penegakan hukum pidana yang berkaitan dengan Integrated Criminal Justice System, yang akhirakhir ini banyak mendapatkan sorotan dari berbagai media massa. Permasalahan yang kerap diangkat ke khalayak ramai yaitu permasalahan pungutan liar (pungli), narkotika dan obat-obatan terlarang (narkoba), ataupun masalah kekerasan dalam penjara. Permasalahan yang ada di dalam Lapas ini timbul disebabkan adanya kelebihan kapasitas sehingga terjadi penumpukan penghuni baik itu narapidana maupun tahanan.

Permasalahan secara umum yang ada di Indonesia, bahwa tingkat kejahatan selalu mengalami kenaikan. Hal ini berdasarkan data Badan Pusat Statistik (BPS) tahun 2015 mengungkapkan bahwa kejadian kejahatan di Indonesia selama periode tahun 20122014 cenderung berfluktuasi. Jumlah kejadian kejahatan atau crime total dari sekitar 341 ribu kasus pada tahun 2012 meningkat menjadi sekitar 342 ribu kasus pada tahun 2013. Namun, pada tahun 2014 menurun menjadi sekitar 325 ribu kasus. Hal ini sejalan dengan risiko penduduk terkena kejahatan (crime rate) 
selama periode Tahun 2012-2014 yang juga berfluktuasi. Jumlah orang yang berisiko terkena tindak kejahatan (crime rate) setiap 100 ribu penduduk diperkirakan sebanyak 134 orang pada tahun 2012,140 orang pada tahun 2013, dan 131 orang pada tahun 2014. Tingkat kejahatan yang ada di Indonesia terjadi penurunan di tahun 2014, kelebihan kapasitas tetap terjadi di semua Lapas dan Rutan di seluruh Indonesia

Data permasalahan di Lapas Kelas IIB Tegal adalah sebagai berikut:

1) Data per tanggal 26 Agustus 2016, jumlah warga binaan (narapidana dan tahanan) 169 orang, kapasitas kamar Lapas sebanyak 150 orang, sehingga ada over kapasitas sebesar 19 orang. Untuk mengatasi permasalahan over kapasitas tersebut, pemerintah seyogyanya perlu memperbanyak kamar hunian ataupun mendirikan Lapas dan Rutan baru diberbagai daerah, sangatlah ironis, disatu pihak kondisi Lapas Kelas IIB Tegal masih terbatas, sedangkan orang yang melakukan tindak kriminal setiap hari bertambah.

2) Permasalahan organisai (budaya kerja) yang sering dihadapi oleh Pemimpin atau Kepala Lapas (Kalapas) Kelas IIB Tegal selama menduduki jabatannya, misalnya kesulitan mengubah budaya yang sudah mendarah daging pada diri pegawai, sebagai contoh sulitnya memberantas pungli.

3) Masalah yang dihadapi pegawai adalah: (1) kurangnya sosialisasi yang dilakukan oleh pegawai organisasi terkait dengan programprogram yang dilaksanakan oleh Lapas terhadap pegawai lain (bidang yang berbeda) dan pada para narapidana; (2) kurangnya pemahaman petugas tentang peraturan yang menjadi landasan operasional dan konseptual pemasyarakatan; (3) ma- sih rendahnya kualitas pendelegasian tugas yang diberikan oleh pegawainya, sehingga tugas-tugas yang diberikan oleh pimpinan tidak tersampaikan sebagaiamana mestinya; (4) adanya pegawai yang tidak mengerti tentang arahan yang diberikan oleh pimpinan. Hal ini disebabkan masih kurangnya pimpinan dan bawahan mengadakan pertemuan baik yang bersifat formal dan informal; (5) adanya pegawai menunda penyelesaian tugas yang diberikan oleh pimpinan; (6) berpakaian dinas tidak sesuai aturan; (7) pelaku indisipliner seperti masuk kantor lambat; (8) pembagian kerja tidak sesuai dengan pelaksanaannya; (9) kurangnya dukungan dari pimpinan, meninggalkan kantor pada jam kerja dan evaluasi bulanan yang sering tidak dilaksanakan.

Mengatasi berbagai permasalahan tersebut, diperlukan seorang pemimpin yang mempunyai gaya kepemimpinan yang mampu menyesuaikan dengan situasi atau lingkungan Lapas. Contohnya seorang pemimpin terkadang harus bersikap otoriter karena gaya kepemimpinan ini dianggap mampu meningkatkan kinerja pegawai di Lapas Kelas IIB Tegal sesuai dengan visi dan misi lembaga pemasyarakatan.

Peningkatan prestasi kerja dari lapas secara keseluruhan dbutuhkan suatu sistem manajemen dalam pengelolaan sumberdaya yang ada, agar visi dan misi dari lapas tersebut dapat tercapai secara optimal. Evaluasi dan solusi secara terpadu diperlukan untuk menghadapi berbagai permasalahan sistem pemasyarakatan, sehingga dapat tercapai kinerja lapas yang lebih baik, maka dilakukan suatu analisis tentang pengaruh gaya kepemimpinan, budaya organisasi dan motivasi terhadap prestasi kerja pegawai lapas kelas IIB Tegal. 


\section{METODE PENELITIAN}

Penelitian ini dirancang dengan tujuan untuk menganalisis hubungan antar variabel. Rancangan penelitian ini termasuk penelitian korelasinal, yaitu penelitian yang dilakukan dengan maksud menganalisis hubungan antar variabel. Variabel-variabel yang digunakan adalah gaya kepemimpinan, budaya organisasi, motivasi kerja dan prestasi kerja sebagaimana diungkapkan dalam hipotesis, masing-masing akan diuraikan dalam indikator yang sesuai dan selanjutnya diturunkan menjadi item pertanyaan dalam instrumen pertanyaan. Data dikumpulkan melalui observasi, wawancara, serta kuesioner yang dilanjutkan dengan uji prasyarat dan uji hipotesis.

Penentuan jumlah sampel dalam penelitian ini menggunakan rumus Slovin. Rumus tersebut dituliskan sebagai berikut (Umar, 2001:47)

$n=\frac{N}{1+N(e)^{2}}$

keterangan:

$\mathrm{n}=$ Jumlah sampel

$\mathrm{N}=$ Jumlah populasi

$\mathrm{e}=$ Tingkat kesalahan

Populasi (N) sebanyak 50 orang pegawai Lapas Kelas IIB Tegal dengan asumsi taraf kesalahan (e) sebesar 5\%, maka jumlah sampel (n) adalah:

$n=\frac{50}{1+50(0.05)^{2}}=44,444 \approx 44$ orang

Maka jumlah sampel dalam penelitian ini adalah sebanyak 44 orang pegawai Lapas Kelas IIB Tegal.

Analisis yang digunakan dalam penelitian ini adalah menggunakan 3 uji yaitu (1) uji prasyarat meliputi uji validitas dan uji reliabilitas, (2) uji hipotesis meliputi uji Fsimultan dan uji t parsial serta (3) uji sampel yang terdiri dari uji heteroskedastisitas, uji normalitas, dan uji multikolinearitas. Dalam menganalisis permasalahan yang dikemukakan dalam penelitian ini, digunakan persamaan regresi berganda, dengan menggunakan Statistical Package for Social Science (SPSS) 20.0.

Secara garis besar, kerangka konseptual peran gaya kepemimpinan, budaya organisasi dan motivasi terhadap peningkatan kinerja pegawai di Lapas Kelas IIB Tegal adalah sebagai berikut :

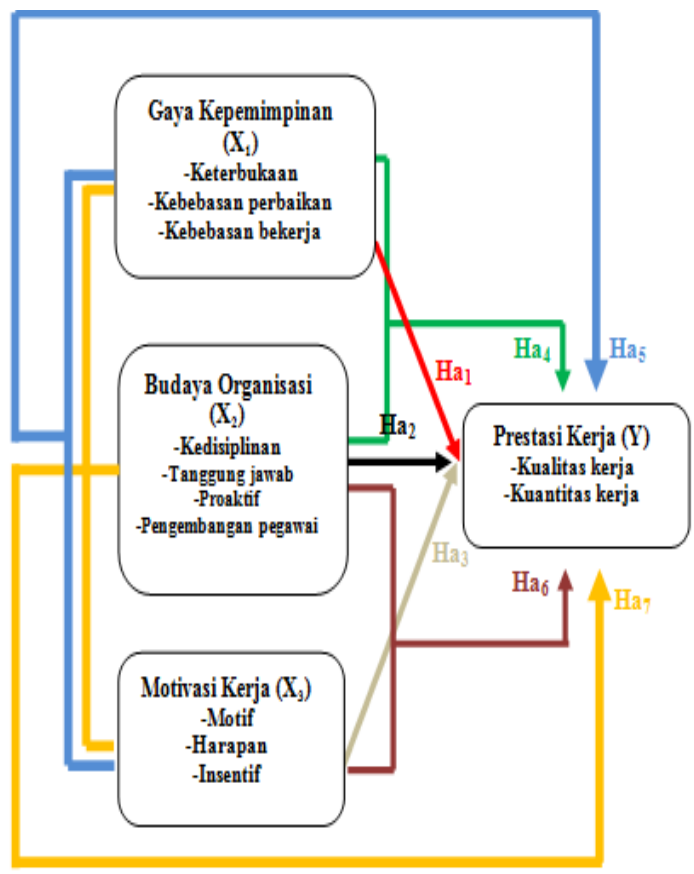

Gambar 1. Kerangka konseptual

\section{HASIL PENELITIAN DAN PEM-}

\section{BAHASAN}

\section{Persamaan Regresi Linear Berganda}

Berdasarkan hasil pengolahan data dengan menggunakan software SPSS 20.0, maka persamaan regresi linear berganda dari data penelitian diperoleh persamaan sebagai berikut:

$Y=4,692+0,526 X 1+0,289 X 2+0,285 X 3$ 
Tabel 1. Data hasil persamaan regresi linear

\begin{tabular}{|c|c|c|}
\hline \multirow{2}{*}{ Variabel } & \multicolumn{2}{|c|}{ Unstander dized Coefficients } \\
\hline & B & Sid Error \\
\hline KONST ANTA & 4,692 & 5,669 \\
\hline $\begin{array}{c}\text { GAYA } \\
\text { KEPEMMIPNNAN }\end{array}$ & 0,526 & 0,296 \\
\hline BUDAYA ORGANSAS & 0,289 & 0,128 \\
\hline NOTIVAS KERIA & 0,285 & 0,097 \\
\hline
\end{tabular}

Persamaan regresi linear yang diperoleh di atas, dapat diketahui bahwa:

$a=$ Kostanta $=4,692$

Artinya bahwa jika tanpa adanya variabel gaya kepemimpinan, budaya organisasi dan motivasi kerja, maka nilai prestasi kerja pegawai di Lapas Kelas IIB Tegal sebesar 4,692, dengan asumsi semua variabel independen dianggap konstan.

\section{b1 $=$ Koefisien regresi variabel gaya kepemimpinan $=\mathbf{0 , 5 2 6}$}

Artinya bahwa nilai variabel gaya kepemimpinan mempengaruhi kenaikan prestasi kerja pegawai sebesar 0,526 . Hal ini menjelaskan bahwa apabila gaya kepemimpinan di Lapas Kelas IIB Tegal naik satu satuan, maka prestasi kerja pegawai juga akan naik sebesar 0,526, dengan asumsi variabel independen yang lain (budaya organisasi dan motivasi kerja) dianggap konstan.

\section{b2 $=$ Koefisien $\quad$ regresi variabel budaya organisasi $=\mathbf{0 , 2 8 9}$ \\ Artinya bahwa nilai variabel} budaya organisasi mempengaruhi kenaikan prestasi kerja pegawai sebesar 0,289. Hal ini menjelaskan bahwa apabila budaya organisasi di Lapas Kelas IIB Tegal naik satu satuan, maka prestasi kerja pegawai juga akan naik sebesar 0,289 , dengan asumsi variabel independen yang lain (gaya kepemimpinan dan motivasi kerja) dianggap konstan.

\section{b3 $=$ Koefisien regresi variabel motivasi kerja $=\mathbf{0 , 2 8 5}$ \\ Artinya bahwa nilai variabel} motivasi kerja mempengaruhi kenaikan prestasi kerja pegawai sebesar 0,285 . Hal ini menjelaskan bahwa apabila motivasi kerja di Lapas Kelas IIB Tegal naik satu satuan, maka prestasi kerja pegawai juga akan naik sebesar 0,285 , dengan asumsi variabel independen yang lain (gaya kepemimpinan dan budaya organisasi) dianggap konstan.

\section{Analisis Koefisien Determinasi $\left(\mathbf{R}^{2}\right)$}

Hasil analisis koefisien determinasi dapat dilihat pada Tabel berikut: Tabel 2. Data regresi antara gaya kepemimpinan, budaya organisasi dan motivasi kerja terhadap prestasi kerja pegawai

\begin{tabular}{|c|c|c|}
\hline $\begin{array}{c}\text { Koefisien Deteminasi } \\
\left(\mathbb{R}^{2}\right)\end{array}$ & $\begin{array}{c}\text { Pengaruh peran gaya kepemimpinan, } \\
\text { budaya organis asi dan motivasi kerja } \\
\text { terhadap prestasi kejja }(\%)\end{array}$ & $\begin{array}{c}\text { Pengaruh variabel } \\
\text { lain (\%) }\end{array}$ \\
\hline 0,4 & 40,0 & 60,0 \\
\hline
\end{tabular}

Sumber. hasil penelitian, 2016 (data diolah)

Besarnya koefisien determinasi $\left(\mathrm{R}^{2}\right)$ sebesar 0,400, artinya konstribusi variabel gaya kepemimpinan, budaya organisasi dan motivasi kerja terhadap prestasi kerja pegawai sebesar 40,0\%, sedangkan $60,0 \%$ dijelaskan oleh variabel lainnya yang tidak diteliti dalam penelitian ini.

\section{Uji Prasyarat (Instrumen)}

Uji instrumen terdiri dari uji validitas dan uji reliabilitas. Instrument dalam penelitian ini berupa kuesioner yang telah disusun dan dibagikan kepada para responden.

\section{a. Uji Validitas instrumen}

Hasil uji validitas dari kuesioner yang telah dibagikan pada responden adalah sebagai berikut: 
Tabel 3. Hasil uji validasi

\begin{tabular}{|c|c|c|c|c|c|}
\hline \multirow{2}{*}{\multicolumn{2}{|c|}{ Variabel }} & \multicolumn{4}{|c|}{ Uji Validitas } \\
\hline & & \multirow{2}{*}{$\begin{array}{c}\text { rhitung } \\
0,597\end{array}$} & \multirow{2}{*}{\begin{tabular}{|c|} 
atau $\rangle$ \\
$>$ \\
\end{tabular}} & \multirow{2}{*}{ itabel } & \multirow{2}{*}{$\begin{array}{c}\text { Hasiluii (data } \\
\text { Valid }\end{array}$} \\
\hline \multirow{3}{*}{ Gaya Kepemimpinan (X1) } & $X 1,1$ & & & & \\
\hline & $\mathrm{X1.2}$ & 0,672 & $>$ & 0,297 & Valid \\
\hline & $\mathrm{X1,3}$ & 0,612 & $>$ & 0,297 & Valid \\
\hline \multirow{8}{*}{ Budaya Organisasi (X2) } & $X 2.1$ & 0,613 & $>$ & 0,297 & Valid \\
\hline & $\times 2.2$ & 0,617 & $>$ & 0,297 & Valid \\
\hline & $\times 2,3$ & 0,416 & $>$ & 0,297 & Valid \\
\hline & $\times 2,4$ & 0,685 & $>$ & 0,297 & Valid \\
\hline & $\times 2.5$ & 0,621 & $>$ & 0,297 & Valid \\
\hline & $\times 2,6$ & 0,618 & $>$ & 0,297 & Valid \\
\hline & $\times 2.7$ & 0,731 & $>$ & 0,297 & Valid \\
\hline & $X 2.8$ & 0,578 & $>$ & 0,297 & Valid \\
\hline \multirow{10}{*}{ Motivasi Kerja(X3) } & $X 3.1$ & 0,493 & $>$ & 0,297 & Valid \\
\hline & $X 3.2$ & 0,558 & $>$ & 0,297 & Valid \\
\hline & $\times 3,3$ & 0,379 & $>$ & 0,297 & Valid \\
\hline & $X 3.4$ & 0,581 & $>$ & 0,297 & Valid \\
\hline & $\times 3.5$ & 0,458 & $>$ & 0,297 & Valid \\
\hline & $\times 3.6$ & 0,563 & $>$ & 0,297 & Valid \\
\hline & $\times 3.7$ & 0,488 & $>$ & 0,297 & Valid \\
\hline & $\times 3.8$ & 0,471 & $>$ & 0,297 & Valid \\
\hline & $\times 3.9$ & 0,526 & $>$ & 0,297 & Valid \\
\hline & $X 3.10$ & 0,423 & $>$ & 0,297 & Valid \\
\hline \multirow{8}{*}{ Prestasi Kerja $(Y)$} & $Y 1$ & 0,665 & $>$ & 0,297 & Valid \\
\hline & $Y 2$ & 0,696 & $>$ & 0,297 & Valid \\
\hline & $Y_{3}$ & 0,686 & $>$ & 0,297 & Valid \\
\hline & $Y_{4}$ & 0,646 & $>$ & 0,297 & Valid \\
\hline & Y5 & 0,598 & $>$ & 0,297 & Valid \\
\hline & $Y 6$ & 0,612 & $>$ & 0,297 & Valid \\
\hline & $Y 7$ & 0,605 & $>$ & 0,297 & Valid \\
\hline & Y8 & 0,614 & $>$ & 0,297 & Valid \\
\hline
\end{tabular}

Berdasarkan tabel 3 diatas, dapat disimpulkan bahwa seluruh pertanyaan kuesioner yang telah dijawab oleh responden bersifat valid karena nilai rhitung $>$ rtabel. Oleh karena itu seluruh item pertanyaan kuesioner dapat digunakan sebagai alat pengumpul data.

\section{b. Uji Reliabilitas instrumen}

Uji reliabilitas dapat dilakukan setelah melakukan uji validitas dari tiap item pertanyaan. Karena semua item pertanyaan dalam penelitian ini dinyatakan valid maka semua item pertanyaan dapat memenuhi untuk pengujian reliabilitas. Keputusan hasil uji reliabilitas dilihat dari hasil nilai Cronbach's Alpha. Kemudian nilai Cronbach's Alpha tersebut dibandingkan dengan nilai $\mathrm{r}_{\text {Tabel }}$ dengan nilai $\mathrm{N}=44$ dicari pada distribusi nilai $\mathrm{r}_{\text {Tabel }}$ pada tingkat signifikasi $5 \%$, yaitu dengan $\mathrm{DF}=$ $\mathrm{N}-2=44-2=42$ maka nilai $\mathrm{r}_{\text {Tabel }}=0,297$
Tabel 4. Hasil uji reliabilitas

\begin{tabular}{|c|c|c|c|c|}
\hline Variabel & Cronbach Alpha & $<$ atau $>$ & $\mathrm{r}_{\text {uzel }}$ & Hasil uji (data) \\
\hline $\begin{array}{c}\text { Gaya } \\
\text { Kepemimpinan } \\
(\mathrm{X} 1)\end{array}$ & 0,448 & $>$ & 0,297 & $\begin{array}{c}\text { Reliabel/ } \\
\text { Handal }\end{array}$ \\
\hline $\begin{array}{c}\text { Budaya Organisasi } \\
\text { (X2) }\end{array}$ & 0,757 & $>$ & 0,297 & $\begin{array}{c}\text { Reliabel/ } \\
\text { Handal }\end{array}$ \\
\hline $\begin{array}{c}\text { Motivasi Kerja } \\
\text { (X3) }\end{array}$ & 0,577 & $>$ & 0,297 & $\begin{array}{c}\text { Reliabel/ } \\
\text { Handal }\end{array}$ \\
\hline Prestasi Kerja (Y) & 0,757 & $>$ & 0,297 & $\begin{array}{c}\text { Reliabel/ } \\
\text { Handal }\end{array}$ \\
\hline
\end{tabular}

Berdasarkan tabel 4, hasil uji reliabititas terhadap semua item pertanyaan pada ke empat variabel (gaya kepemimpinan, budaya organisasi, motivasi kerja dan prestasi kerja) dapat disimpulkan bahwa nilai Cronbach Alpha >, artinya item-item kuesioner pada keempat variabel (gaya kepemimpinana, budaya organisasi, motivasi kerja dan prestasi kerja) dapat dikatakan reliabel atau terpercaya sebagai alat pengumpul data dalam penelitian ini.

\section{Uji Sampel}

Suatu model regresi linear dapat digunakan atau tidak, maka terlebih dahulu dilakukan uji sampel yaitu normalitas, multikolinearitas dan Heteroskedastisitas.

\section{a. Uji Normalitas}

Untuk mengetahui dalam suatu data berdistribusi normal atau tidak, maka digunakan uji KolmogorovSmirnov. Bila nilai signifikasi $>\alpha$ $(0,05)$, maka data berdistribusi normal. Hasil uji normalitas variabel gaya kepemimpinan, budaya organisasi dan motivasi kerja terhadap prestasi kerja dapat dilihat pada Tabel 5.

Tabel 5. Hasil uji normalitas

\begin{tabular}{|c|c|c|c|c|}
\hline $\begin{array}{c}\text { Unstandardized } \\
\text { Residual }\end{array}$ & $\begin{array}{c}\text { GAYA } \\
\text { KEPEMIMPNAN }\end{array}$ & $\begin{array}{c}\text { BUDAYA } \\
\text { ORGANISASI }\end{array}$ & $\begin{array}{c}\text { MOTIVASI } \\
\text { KERJA }\end{array}$ & $\begin{array}{c}\text { PRESTASI } \\
\text { KERJA }\end{array}$ \\
\hline $\begin{array}{c}\text { Asymp. Sig. } \\
\text { (2-tailed) }\end{array}$ & 0,083 & 0,762 & 0,541 & 0,482 \\
\hline
\end{tabular}

Tabel 5 dapat dilihat bahwa nilai signifikasi (Sig) Kolmogorov-Smirnov untuk variabel gaya kepemimpinan, 
budaya organisasi, motivasi kerja dan prestasi kerja masing-masing adalah 0,$082 ; 0,762 ; 0,541 ; 0,482>\alpha(0,05)$. Kesimpulan hasil Tabel di atas bahwa data berdistribusi normal untuk masingmasing variabel gaya kepemimpin, budaya organisasi, motivasi kerja dan prestasi kerja.

\section{b. Uji Multikolinearitas}

Uji multikolinearitas ini bertujuan untuk mengetahui apakah model regresi linear ditemukan adanya korelasi yang tinggi di atara variabel independen. Model regresi yang baik adalah tidak terjadi multikolinearitas. Untuk mendeteksi tidak adanya multikolineritas didalam model regresi digunakan uji nilai tolerance $>0,1$ dan nilai Variance Inflation Factor (VIF) < 10.

Tabel 6. Hasil uji multikolinearitas.

\begin{tabular}{|c|c|c|c|}
\hline \multicolumn{2}{|c|}{ Variabel } & \multicolumn{2}{c|}{ Collinearity Statistics } \\
\cline { 3 - 4 } & & Tolerance & VIF \\
\hline 1 & Gaya Kepermimpinan & 0,977 & 1,023 \\
\hline 2 & Budaya Organisasi & 0,841 & 1,189 \\
\hline 3 & Motivasi Kerja & 0,856 & 1,168 \\
\hline
\end{tabular}

Berdasarkan Tabel 6, dapat dilihat bahwa:

(1) Nilai tolerance gaya kepemimpinan terhadap prestasi kerja $0,977>0,1$, dan nilai VIF $1,023<10$. Sehingga dapat disimpulkan bahwa data tidak terjadi multikolinearitas.

(2) Nilai tolerance budaya organisasi terhadap prestasi kerja $0,841>0,1$, dan nilai VIF $1,199<10$. Sehingga dapat disimpulkan bahwa data tidak terjadi multikolinearitas.

(3) Nilai tolerance motivasi kerja terhadap prestasi kerja $0,856>0,1$, dan nilai VIF $1,168<10$. Sehingga dapat disimpulkan bahwa data tidak terjadi multikolinearitas.

\section{c. Uji Heteroskedastisitas}

Uji Heteroskedastisitas ini bertujuan untuk menguji model regresi terjadi ketidaksamaan variance. Model regresi yang baik tidak terjadi Heteroskedastisitas. Dengan dasar pengambilan keputusan dilihat dari nilai Signifikansi (Sig). Jika nilai Sig $>0,05$, maka tidak terjadi Heteroskedastisitas.

Tabel 7. Hasil uji heteroskedastisitas

\begin{tabular}{|c|c|}
\hline Variabel & Nilai Sig. \\
\hline Gaya Kepemimpinan & 0,093 \\
Budaya Organisasi & 0,910 \\
Motivasi Kerja & 0,860 \\
\hline
\end{tabular}

Tabel 7 di atas, dapat dilihat bahwa nilai sig dari variabel gaya kepemimpinan $=0,093>0,05$, nilai sig variabel budaya organisasi $=0,910>$ 0,05 , dan nilai sig variabel motivasi kerja $=0,860>0,05$ sehingga dapat disimpulkan bahwa data tidak terjadi Heteroskedastisitas.

\section{Uji Hipotesis}

Berdasarkan tujuan penelitian dan ketujuh kerangka konseptual penelitian, maka akan dilakukan analisis secara parsial dan simultan. Analisis parsial dilakukan untuk Ha1, Ha2 dan $\mathrm{Ha} 3$, sedangkan analisis simultan dilakukan untuk Ha4, Ha5, Ha6 dan Ha7.

\section{a. Uji Parsial}

Pengujian hipotesis secara parsial menggunakan uji $\mathrm{t}$ dengan syarat pengambilan keputusan apabila thitung $>$ tTabel, dan nilai signifikasi $<0,005$ maka H0 ditolak Ha diterima, sebaliknya thitung < ttabel, dan nilai signifikasi $>$ 0,005 maka H0 diterima dan Ha ditolak. ttabel dilihat berdasarkan nilai degree of freedom (df) yaitu pengurangan jumlah responden dengan jumlah variabel penelitian yang dianalisis dan tingkat kesalahan/signifikasi. Pada penelitian ini menggunakan $\mathrm{df}=\mathrm{N}-\mathrm{k}=44-4=40$, dengan tingkat kesalahan/signifikasi sebesar 5\%, maka nilai ttabel $(0,05 ; 40)=$ 1,682 . 


\section{1) Pengujian Hipotesis 1}

Analisis pengujian hipotesis pertama:

$\mathrm{H} 0=$ Gaya kepemimpinan tidak berpengaruh positif dan signifikan terhadap prestasi kerja pegawai di Lapas Kelas IIB Tegal

$\mathrm{Ha}_{1}=$ Gaya kepemimpinan berpengaruh positif dan signifikan terhadap prestasi kerja pegawai di Lapas Kelas IIB Tegal.

Hasil pengujian $\mathrm{t}$ parsial untuk hipotesis pertama dapat dilihat dari Tabel 8 berikut ini:

Tabel 8. Hasil uji t-parsial pada variabel gaya kepemimpinan, terhadap prestasi kerja

\begin{tabular}{|c|c|c|}
\hline Variabel & $\mathrm{t}$ & $\mathrm{Sig}$. \\
\hline Gaya Kepemimpinan & 1,726 & 0,042 \\
\hline
\end{tabular}

Hasil Tabel 8 dapat disimpulkan bahwa variabel gaya kepemimpinan berpengaruh positif dan siginifikan terhadap prestasi kerja pegawai di Lapas Kelas IIB Tegal. Hal ini terlihat dari nilai thitung $(1,726)>$ tTabel $(1,682)$, dan berdasarkan nilai signifikasinya $0,042<0,05$ maka artinya H0 ditolak, dan Ha1 diterima, yaitu"Terdapat pengaruh positif dan signifikan gaya kepemimpinan terhadap prestasi kerja pegawai di Lapas Kelas IIB Tegal”.

\section{2) Pengujian Hipotesis 2}

kedua:

Analisis pengujian hipotesis

$\mathrm{H} 0$ = Budaya organisasi tidak berpengaruh positif dan signifikan terhadap prestasi kerja pegawai di Lapas Kelas IIB Tegal

$\mathrm{Ha} 2$ = Budaya organisasi berpengaruh positif dan signifikan terhadap prestasi kerja pegawai di Lapas Kelas IIB Tegal.

Hasil pengujian $\mathrm{t}$ parsial untuk hipotesis kedua dapat dilihat dari Tabel 9 berikut ini:
Tabel 9. Hasil uji t-parsial pada variabel budaya organisasi terhadap prestasi kerja

\begin{tabular}{|c|c|c|}
\hline Variabel & $\mathrm{t}$ & Sig. \\
\hline Budaya Organisasi & 3,575 & 0,001 \\
\hline
\end{tabular}

Hasil Tabel 9 di atas dapat disimpulkan bahwa variabel budaya organisasi berpengaruh positif dan siginifikan terhadap prestasi kerja pegawai di Lapas Kelas IIB Tegal. Hal ini terlihat dari nilai $t_{\text {hitung }}(3,575)>\mathrm{t}_{\text {Tabel }}$ $(1,682)$, dan berdasarkan nilai signifikasinya $0,001<0,05$ maka artinya $\mathrm{H} 0$ ditolak, dan $\mathrm{Ha}_{2}$ diterima, yaitu "Terdapat pengaruh positif dan signifikan budaya organisasi terhadap prestasi kerja pegawai di Lapas Kelas IIB Tegal”.

\section{3) Pengujian Hipotesis 3}

Analisis pengujian hipotesis ketiga:

$\mathrm{H} 0=$ Motivasi kerja tidak berpengaruh positif dan signifikan terhadap prestasi kerja pegawai di Lapas Kelas IIB Tegal

$\mathrm{Ha}_{3}=$ Motivasi kerja berpengaruh positif dan signifikan terhadap prestasi kerja pegawai di Lapas Kelas IIB Tegal.

Hasil pengujian $\mathrm{t}$ parsial untuk hipotesis ketiga dapat dilihat dari Tabel 10 berikut ini:

Tabel 10. Hasil uji t-parsial pada variabel motivasi kerja terhadap prestasi kerja

\begin{tabular}{|c|c|c|}
\hline Model & $\mathrm{t}$ & Sig. \\
\hline Motivasi Kerja & 3,370 & 0,002 \\
\hline
\end{tabular}

Hasil Tabel 10 di atas, dapat disimpulkan bahwa variabel motivasi kerja berpengaruh positif dan siginifikan terhadap prestasi kerja pegawai di Lapas Kelas IIB Tegal. Hal ini terlihat dari nilai $t_{\text {hitung }}(3,370)>t_{\text {Tabel }}(1,682)$, dan 
berdasarkan nilai signifikasinya $0,002<0,05$ maka artinya H0 ditolak, dan $\mathrm{Ha}_{3}$ diterima, yaitu'Terdapat pengaruh positif dan signifikan motifasi kerja terhadap prestasi kerja pegawai di Lapas Kelas IIB Tegal”.

\section{b. Uji Simultan}

Pengujian hipotesis secara simultan menggunakan uji $\mathrm{F}$ dengan syarat pengambilan keputusan apabila $\mathrm{F}_{\text {hitung }}>\mathrm{F}_{\text {Tabel, }}$, dan nilai signifikasi < 0,005 maka H0 ditolak Ha diterima, sebaliknya $\mathrm{F}_{\text {hitung }}<\mathrm{F}_{\text {Tabel, }}$, dan nilai signifikasi $>0,005$ maka $\mathrm{H} 0$ diterima dan Ha ditolak. FTabel dilihat berdasarkan nilai degree of freedom (df) yaitu $\operatorname{df}(\mathrm{n} 1)$ dan $\mathrm{df}(\mathrm{n} 2)$.

$\mathrm{df}(\mathrm{n} 1)=\mathrm{k}-1$

df $(n 2)=N-k$

keterangan:

$\mathrm{k}=$ jumlah variabel independen

$\mathrm{N}=$ jumlah responden

Tabel $F$ dilihat padat tingkat kesalahan/signifikasi sebesar 5\%.

\section{1) Pengujian Hipotesis 4}

Berikut ini adalah analisis pengujian hipotesis keempat:

$\mathrm{H} 0$ = Gaya kepemimpian dan budaya organisasi secara simultan tidak berpengaruh positif dan signifikan terhadap prestasi kerja pegawai di Lapas Kelas IIB Tegal

$\mathrm{Ha}_{4}=$ Gaya kepemimpian dan budaya organisasi simultan berpengaruh positif dan signifikan terhadap prestasi kerja pegawai di Lapas Kelas IIB Tegal.

Tabel $F$ dilihat padat tingkat kesalahan/signifikasi sebesar 5\%, maka nilai $\mathrm{F}_{\text {Tabel }(1 ; 42)}=4,07$. Hasil pengujian $\mathrm{F}$ simultan untuk hipotesis keempat dapat dilihat dari Tabel 11 berikut ini:
Tabel 11. Hasil uji F-simultan pada variabel gaya kepemimpinan dan budaya organisasi terhadap prestasi kerja.

\begin{tabular}{|c|c|}
\hline Nilai F & Nilai Sig. \\
\hline 7,628 & 0,002 \\
\hline
\end{tabular}

Hasil Tabel 11 di atas, maka dapat disimpulkan bahwa variabel gaya kepemimpianan dan budaya organisasi secara simultan berpengaruh positif dan signifikan terhadap prestasi kerja pegawai di Lapas Kelas IIB Tegal. Hal ini terlihat dari nilai $F_{\text {hitung }}(7,628)>$ $\mathrm{F}_{\text {Tabel }}(4,07)$, dan berdasarkan nilai signifikasinya $0,002<0,05$ maka artinya $\mathrm{H0}$ ditolak dan $\mathrm{Ha}_{4}$ diterima, yaitu "Terdapat pengaruh positif dan signifikan secara simultan antara gaya kepemimpinan dan budaya organisasi terhadap prestasi kerja pegawai di Lapas Kelas IIB Tegal".

\section{2) Pengujian Hipotesis 5}

kelima:

Analisis pengujian hipotesis

$\mathrm{H} 0=$ Gaya kepemimpian dan motivasi kerja secara simultan tidak berpengaruh positif dan signifikan terhadap prestasi kerja pegawai di Lapas Kelas IIB Tegal

$\mathrm{Ha}_{5}=$ Gaya kepemimpian dan motivasi kerja secara simultan berpengaruh positif dan signifikan terhadap prestasi kerja pegawai di Lapas Kelas IIB Tegal.

Tabel $F$ dilihat padat tingkat kesalahan/signifikasi sebesar 5\%, maka nilai $\mathrm{F}_{\text {Tabel }(1 ; 42)}=4,07$. Hasil pengujian $\mathrm{F}$ simultan untuk hipotesis kelima dapat dilihat dari Tabel 12.

Tabel 12. Hasil uji F-simultan pada variabel gaya kepemimpinan dan motivasi kerja terhadap prestasi kerja

\begin{tabular}{|c|c|}
\hline Nilai F & Nilai Sig. \\
\hline 8,079 & 0,001 \\
\hline
\end{tabular}


Hasil Tabel 12 di atas, maka dapat disimpulkan bahwa variabel gaya kepemimpianan dan motivasi kerja secara simultan berpengaruh positif dan siginifikan terhadap prestasi kerja pegawai di Lapas Kelas IIB Tegal. Hal ini terlihat dari nilai $F_{\text {hitung }}(8,079)>$ $F_{\text {Tabel }}(4,07)$, dan berdasarkan nilai signifikasinya $0,001<0,05$ maka artinya $\mathrm{H} 0$ ditolak, dan $\mathrm{Ha}_{5}$ diterima, yaitu "Terdapat pengaruh positif dan signifikan secara simultan antara gaya kepemimpinan dan motivasi kerja terhadap prestasi kerja pegawai di Lapas Kelas IIB Tegal".

\section{3) Pengujian Hipotesis 6}

Analisis pengujian hipotesis keenam:

$\mathrm{HO}=$ Budaya organisasi dan motivasi kerja secara simultan tidak berpengaruh positif dan signifikan terhadap prestasi kerja pegawai di Lapas Kelas IIB Tegal

$\mathrm{Ha}_{6}=$ Budaya organisasi dan motivasi kerja secara simultan berpengaruh positif dan signifikan terhadap prestasi kerja pegawai di Lapas Kelas IIB Tegal.

Tabel $F$ dilihat padat tingkat kesalahan/signifikasi sebesar 5\%, maka nilai $\mathrm{F}_{\text {Tabel(1;42) }}=4,07$. Hasil pengujian $\mathrm{F}$ simultan untuk hipotesis keenam dapat dilihat dari Tabel 13 berikut ini:

Tabel 13. Hasil uji F-simultan pada variabel budaya organisasi dan motivasi kerja terhadap prestasi kerja

\begin{tabular}{|c|c|}
\hline Nilai F & Nilai Sig. \\
\hline 9,870 & 0,000 \\
\hline
\end{tabular}

Hasil Tabel 13 di atas, maka dapat disimpulkan bahwa variabel budaya organisasi dan motivasi kerja secara simultan berpengaruh positif dan siginifikan terhadap prestasi kerja pegawai di Lapas Kelas IIB Tegal. Hal ini terlihat dari nilai $F_{\text {hitung }}(9,870)>$ $\mathrm{F}_{\text {Tabel }}(4,07)$, dan berdasarkan nilai signifikasinya $0,000<0,05$ maka artinya $\mathrm{H} 0$ ditolak, dan $\mathrm{Ha}_{6}$ diterima, yaitu "Terdapat pengaruh positif dan signifikan secara simultan antara budaya organisasi dan motivasi kerja terhadap prestasi kerja pegawai di Lapas Kelas IIB Tegal".

\section{4) Pengujian Hipotesis 7}

Berikut ini adalah analisis pengujian hipotesis ketujuh:

$\mathrm{HO}=$ Gaya kepemimpinan, budaya organisasi dan motivasi kerja secara simultan tidak berpengaruh positif dan signifikan terhadap prestasi kerja pegawai di Lapas Kelas IIB Tegal

$\mathrm{Ha}_{7}=$ Gaya kepemimpinan, budaya organisasi dan motivasi kerja secara simultan berpengaruh positif dan signifikan terhadap prestasi kerja pegawai di Lapas Kelas IIB Tegal.

Tabel $\mathrm{F}$ dilihat padat tingkat kesalahan/signifikasi sebesar 5\%, maka nilai $\mathrm{F}_{\text {Tabel }(2 ; 41)}=3,23$. Hasil pengujian $\mathrm{F}$ simultan untuk hipotesis keenam dapat dilihat dari Tabel 14 berikut ini:

Tabel 14. Hasil uji F-simultan pada variabel budaya organisasi dan motivasi kerja terhadap prestasi kerja

\begin{tabular}{|c|c|}
\hline NilaiF & Nilai Sig- \\
\hline 7.892 & 0.000 \\
\hline
\end{tabular}

Hasil Tabel 33 di atas, maka dapat disimpulkan bahwa variabel gaya kepemimpinan, budaya organisasi dan motivasi kerja secara simultan berpengaruh positif dan siginifikan terhadap prestasi kerja pegawai di Lapas Kelas IIB Tegal. Hal ini terlihat dari nilai $F_{\text {hitung }}(7,892)>$ $\mathrm{F}_{\text {Tabel }}(3,23)$, dan berdasarkan nilai signifikasinya $0,000<0,05$ maka artinya $\mathrm{HO}$ ditolak, dan $\mathrm{Ha}_{7}$ diterima, yaitu 
"Terdapat pengaruh positif dan signifikan secara simultan antara gaya kepemimpinan, budaya organisasi dan motivasi kerja terhadap prestasi kerja pegawai di Lapas Kelas IIB Tegal”.

\section{KESIMPULAN}

Berdasarkan hasil analisis data dan pembahasan pada penelitian ini dapat disimpulkan sebagai berikut:

1. Hasil analisis data penelitian pada uji t-parsial menunjukkan bahwa gaya kepemimpian berperngaruh positif dan signifikan terhadap prestasi kerja pegawai di Lapas Kelas IIB Tegal.

2. Hasil analisis data penelitian pada uji t-parsial menunjukkan bahwa budaya organisasi berperngaruh positif dan signifikan terhadap prestasi kerja pegawai di Lapas Kelas IIB Tegal.

3. Hasil analisis data penelitian pada uji t-parsial menunjukkan bahwa motivasi kerja berpengaruh positif dan signifikan terhadap prestasi kerja pegawai di Lapas Kelas IIB Tegal.

4. Hasil analisis data penelitian pada uji F-simultan menunjukkan bahwa gaya kepemimpinan dan budaya organisasi secara simultan berperngaruh positif dan signifikan terhadap prestasi kerja pegawai di Lapas Kelas IIB Tegal.

5. Hasil analisis data penelitian pada uji F-simultan menunjukkan bahwa gaya kepemimpinan dan motivasi kerja secara simultan berperngaruh positif dan signifikan terhadap prestasi kerja pegawai di Lapas Kelas IIB Tegal.

6. Hasil analisis data penelitian pada uji F-simultan menunjukkan bahwa budaya organisasi dan motivasi kerja secara simultan berperngaruh positif dan signifikan terhadap prestasi kerja pegawai di Lapas Kelas IIB Tegal.

7. Hasil analisis data penelitian pada uji F-simultan menunjukkan bahwa gaya kepemimpinan, budaya organisasi dan motivasi kerja secara simultan berperngaruh positif dan signifikan terhadap prestasi kerja pegawai di Lapas Kelas IIB Tegal.

8. Dari ketujuh hasil analisis data hasil uji hipotesis dapat tarik kesimpulan jika ketiga variabel independen (gaya kepemimpinan, budaya organisasi dan motivasi kerja) berpengaruh secara positif dan signifikan, baik secara parsial maupun simultan terhadap prestasi kerja pegawai di Lapas Kelas IIB Tegal

\section{DAFTAR PUSTAKA}

Buku:

Arikunto, Suharsim. 2006. Prosedur Penelitian Suatu Pendekatan Praktek. Jakarta: Rineka Cipta.

Badan Pusat Statistik. 2015. Statistik Kriminal 2015. Hak Cipta Badan Pusat Statistik RI, didownload di www.bps.go.id tanggal 15 Juli 2016.

Fred C, Lunenburg. 2011. Understanding OrganizationalCulture: A Key Leadership Asset, National Forum of Educational Administration and Supervisior. Journal Volume 29. Number 4.

Fuad Mas'ud, 2004. Survey Diagnosis Organisasional. Edisi keenam Jilid 2. Semarang: Universitas Diponogoro.

Ghozali, Imam. 2005. Aplikasi Analisis Multivariate dengan Program SPSS. Edisi Ketiga. Badan Penerbit Universitas Diponegoro. Semarang. 
Handoko, T, Hani. 2001. Manajemen Personalia dan Sumberdaya Manusia. Yogyakarta: BPFE UGM.

Hanke,E dan Reitsch,G. 1995. Bussiness Forecasting. Sixth Edition. New Jersey: Prentice Hall.

Hasibuan, SP, Malayu . 2002. Organisasi dan Motivasi Dasar. Jakarta: PT. Bumi Aksara.

Hasibuan, S,P, Malayu. 2008. Manajemen Sumberdaya Manusia. Jakarta: PT Bumi Aksara.

Hersey. 2004. Kunci Sukses Pemimpin Situasional. Jakarta Delaprasata.

Ivancevich JM., Konopaske R, dan Matteson MT. 2006. Perilaku dan Manajemen Organisasi. Jilid 1 dan 2 Edisi ketujuh Erlangga. Jakarta.

Kartono, Kartini. 2005. Pemimpin dan Kepemimpinan. PT Raja Grafindo Persada. Jakarta.

Kreitner, Robert dan Kinicki, Angelo. 2003. Perilaku Organisasi. Edisi pertama buku 1 Salemba Empat. Jakarta.

Mangkunegara, A dan Anwar Prabu. 2008. Manajemen Sumberdaya Manusia Perusahaan, Cetakan Ketujuh. Penerbit PT Remaja Rosdakarya. Bandung.

Manullang. 2008. Dasar-dasar Manajemen. Penerbit: Gajah Mada University Press, Jogjakarta

Munandar, Haris. 1995. Keberhasilan dan Pengaruh Dalam Manajemen. Penerbit: Maju Bandung. Bandung.

Nasution, Mulia. 2000. Manajemen Personalia. Jakarta: Djambatan.

Nawawi, Hadari. 2006. Kepemimpinan yang Efektif. Gajah Mada Unicity Press. Yogyakarta.

Nitisemito, Alex. 1997. Manajemen Personalia (Manajemen Sumber Daya Manusia) Edisi Ketiga. Cetakan Kesembilan. Ghalia Indonesia. Jakarta

Rivai, Veithzal. 2004. Kepemimpinan dan Perilaku Organisasi. Edisi Kedua. Jakarta: PT Raja Grafindo Persada.

Robbins, Stephen P. 2006. Perilaku Keorganisasian. Jilid 1 Edisi 9. Jakarta: PT Indeks kelompok Gramedia.

Schein, EH. 1992. Organizational Culture and Leadership. Penerbit: San Fransisco: JosseyBass.

Siagian, Sondang P. 1997. Teori Motivasi dan Aplikasinya. Rineka Cipta, Jakarta.

Singarimbun dan Effendy. 1995. Metode Penelitian Survei. Cetakan Kedua Penerbit PT. Pustaka LP3ES. Jakarta.

Soetjipto, Budi,dkk. 2002. Paradigma Baru Manajemen Sumber Daya Manusia. Penerbit: Amara Books

Sudjana. 2000. Metode Statistika. Bandung: Tarsito

Sugiyono. 2011. Metode Penelitian Kuantitatif Kualitatif Dan R\&D. Bandung: Alfabeta 
Sujak, Abi. 2000. Manajemen Personalia. Edisi Kelima, Cetakan Pertama. Yogyakarta BPFE.

Umar, Husein. 2001. Riset Sumberdaya Manusia. PT SUN. Jakarta.

Tika, MP. 2006. Budaya Organisasi dan Peningkatan Kinerja Perusahaan. Jakarta : Bumi Aksara.

Taylor, Frederick Winslow. 1916. The Princples of Management. California.

Umar, Husein, 2001. Riset Sumber Daya Manusia. PT.SUN. Jakarta

Yukl, Gary. 1994. Leadership in Organizations. Third Edition Prentice Hall. Englewood Cliffs.

\section{Jurnal Penelitian:}

Gunawan Ketut. 2009. Pengaruh Budaya Organisasi, Kepuasan Kerja dan Motivasi Kerja terhadap gaya Kepemimpinan dan Kinerja Organisasi- Studi pada Lembaga Perkreditan Desa (LPD) di Bali. Jurnal Aplikasi Manajemen Volume 7 No 2-Mei.

Reddy, Anurandha. 2011. Impact Of Transformational And Transactional Leadership On Employee Job Performance And Job Satisfication In Uae Banking Sector. Zenith International Journal Of Business Economics \& Management Research Vol. 1 Issue No.2, Nov 2011

Ria Satyawati dan Wayan Suartana. 2014. Pengaruh Gaya Kepemimpinan Dan Budaya Organisasi Terhadap Kepuasan Kerja Yang Berdampak Pada Kinerja Keuangan. E-jurnal Akuntansi Universitas Udayana hal 61.

Rizkiyani Dwi dan Saragih Susanti. 2012. Stress Kerja Dan Motivasi Kerja Pada Petugas Lembaga Pemasyarakatan. Jurnal Manajemen Vol 12 No 1. November 2012. Universitas Maranatha.

Sihite Hasnawati Tiurlina. 2012. Pengaruh Pendidikan dan Pelatihan (Diklat) Serta Motivasi Terhadap Kinerja Pegawai Di Sekretariat Daerah Kabupaten Tapanuli Tengah. Universitas Terbuka, Jakarta.

Teguh, Rhiman, Handoko. 2012. Pengaruh Kepemimpinan, Budaya Organisasi Dan Disiplin Kerja Terhadap kinerja Karyawan Pada Pondok Serrata Hotel. Didownload dari www.journal.usm.ac.id, pada tanggal 21 Juli 2016.

Wibowo, Triyoga Agung, Intan Ratnawati, Eisha Latanuva dan Ismi Darmastuti, 2007. Analisis Pengaruh Budaya Organisasi dan Kepuasan Kerja terhadap Motivasi Kerja dan Kinerja Karyawan (Studi Pada Kantor Unit Cabang BRI Pattimura Semarang). Jurnal Manajemen dan Organisasi, Vol 4, No 1, didownload tanggal 27 Juli 2016.dari http://eprints.undip.ac.id/411/1/JMO_Vol_4_No_1.pdf

Yusianto. Rendra. 2012. Analisis Pengaruh Stres Kerja Terhadap Prestasi Kerja Staf Pengajar (Studi Kasus Fakultas Ilmu Komputer Universitas Dian Nuswantoro Semarang). www.jounal.uii.ac.id. diakses tanggal 26 Juli 2016. 


\section{Tesis:}

Ika Merdiana, S. 2013. Pengaruh Kepemimpinan dan Motivasi Terhadap Kinerja Pegawai Melalui Kepuasan Di Sekretariat Daerah Kota Surakarta . Tesis: Stie AUB Surakarta.

\section{Peraturan Perundang-Undangan:}

. Undang - Undang Nomor 12 Tahun 1995. Tentang Pemasyarakatan.

Kepegawaian.

. Undang - Undang Nomor 43 Tahun 1999. Tentang Pokok-Pokok Keputusan Presiden RI No. 87 Tahun 1999. Tentang Rumpun Jabatan Fungsional Pegawai Negeri Sipil.

. Peraturan Pemerintah Nomor 54 Tahun 2003. Tentang Formasi Pegawai Negeri Sipil.

Peraturan Presiden Nomor 4 Tahun 2007. Tentang Penyesuaian Gaji Pokok Pegawai Negeri Sipil.

Peraturan Pemerintah Nomor 7 Tahun 1997. Tentang Peraturan Gaji Pegawai Negeri Sipil.

Peraturan Presiden Nomor 21 Tahun 2006. Tentang Penyesuaian Tunjangan Pemasyarakatan.

Keputusan Menteri Hukum dan Hak Asasi Manusia RI No.M.01KP.01.05 Tahun 1994 tanggal 8 Februari 1994. Tentang Pola Penjenjangan Karir Pejabat Pemasyarakatan Departemen Hukum dan Hak Asasi Manusia

Peraturan Menteri Hukum dan Hak Asasi Manusia RI No.M.09-

PR.07.01 Tahun 2007. Tentang Orta Departemen Hukum dan Hak Asasi Manusia. 